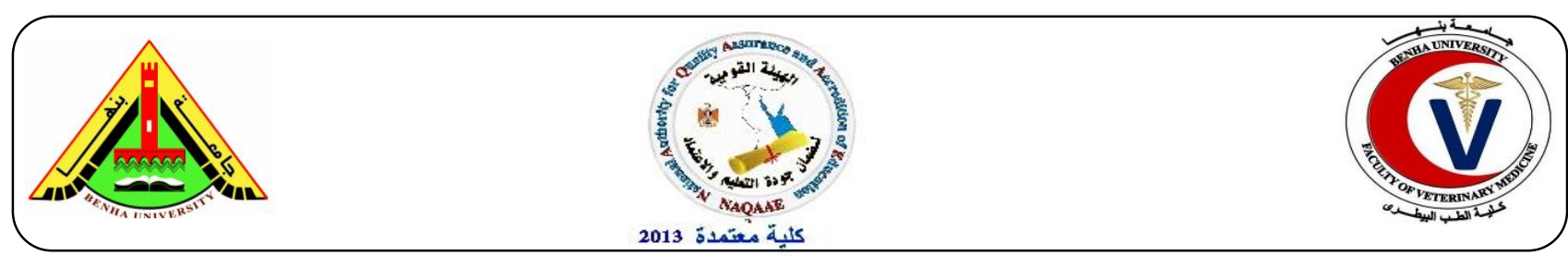

\title{
Synergistic curative effect of Boswellic acid and Cisplatin against Diethyl nitrosamine -induced hepatocellular carcinoma
}

\author{
Omayma A.R. AboZaid ${ }^{1}$, Omnia M. Abd El-Hamid ${ }^{1}$, Somaya Z. Mansour ${ }^{2}$, Abeer E. El-Gendy ${ }^{3}$ \\ ${ }^{I}$ Department of Biochemistry, Faculty of Veterinary Medicine, Benha University \\ ${ }^{2}$ Department of Radiation Biology, National Centre for Radiation Research and Technology, Egypt \\ ${ }^{3}$ Department of Biochemistry, Faculty of Science, Tanta University
}

\begin{abstract}
A B S T R A C T
Hepatocellular carcinoma (HCC) is a primary malignancy of hepatocyte. Boswellic acids are the effective components of gum resin of Boswellia serrata, which have anti-inflammatory properties. Cisplatin is used as a chemotherapeutic agent for treatment of HCC. The present study aims to evaluate the role of Boswellic acid in HCC treatment and as a chemo-sensitizer for Cisplatin treatment of HCC in rats that is induced by orally administration of Diethyl nitrosamine (DEN). Sixty rats were divided in to sex groups, 10 rats each, group 1: normal control group, group 2: cisplatin $(1.5 \mathrm{mg} / \mathrm{Kg} \mathrm{b} . \mathrm{wt})$, group 3: received the Diethyl nitrosamine (DEN) $(20 \mathrm{mg} / \mathrm{kg} \mathrm{b.wt),} \mathrm{group} \mathrm{4:} \mathrm{received} \mathrm{DEN} \mathrm{as} \mathrm{in} \mathrm{group} 3$ and then treated with cisplatin, group 5: received DEN as in group 3 and then treated with Boswellic acid $(500 \mathrm{mg} / \mathrm{kg} \mathrm{b.wt})$ and group 6: received DEN as in group 3 and then treated with cisplatin and Boswellic acid. After 10 weeks animals were sacrificed and liver tissue were removed for Histopathological and tissue parameters examination. A significant increase in serum alanine aminotransferase (ALT), aspartate aminotransferase (AST) activity, a significant decrease in serum albumin concentration. Also a significant increases in liver transforming growth factor-beta 1 (TGF-b1), B-cell lymphoma 2 (Bcl-2) and nuclear factor kappa $\beta$ (NF-k $\beta$ ) concentrations and a significant decrease in Caspase. 3 activity were recorded in DEN-treated rats while treatment with Boswellic acid and Cisplatin reduced the severity of HCC and enhanced histopathological findings, these result suggesting the efficacy of Boswellic acid supplementation as an anti-HCC.
\end{abstract}

Keywords: HCC, Boswellic acid, BCL2, NF-k $\beta$ and Caspase. 3

(http://www.bvmj.bu.edu.eg)

(BVMJ-36(2): 256-263, 2019)

\section{INTRODUCTION}

The incidence of liver cancer is one of the highest in the world. It is up to $90 \%$ of all liver malignancies. In Egypt, HCC constitutes a significant public health problem and responsible for $33.63 \%$ and $13.54 \%$ of all cancers in males and females respectively. Hepatocellular carcinoma occurs in a number of preexisting conditions that commonly includes hepatitis $\mathrm{C}$ and $\mathrm{B}$, alcoholic and nonalcoholic cirrhosis. It has a poor prognosis after discovery. This had been strongly linked to the hepatitis $\mathrm{C}$ virus epidemic that affected around 10-15\% of the Egyptian population during the last 3 decades, and was reported as the highest prevalence of $\mathrm{HCV}$ in the world (Elghazaly et al., 2019).

Diethyl nitrosamine (DEN) is a strong hepatocarcinogenic substance that causes disturbances in nucleic acid repair mechanisms and also generates reactive oxygen species
(ROS) leading to oxidative stress (Fazal et al., 2017).

Cisplatin or cis-diamminedichloroplatinum (II), is a well-known chemotherapeutic drug. It has been used for treatment of numerous human cancers including bladder, head and neck, lung, ovarian, and testicular cancers. It is effective against various types of cancers, including carcinomas, germ cell tumors, lymphomas, and sarcomas. Its mode of action has been linked to its ability to crosslink with the purine bases on the DNA; interfering with DNA repair mechanisms, causing DNA damage, and subsequently inducing apoptosis in cancer cells. However, because of drug resistance and numerous undesirable side effects such as severe kidney problems, allergic reactions, decrease immunity to infections, gastrointestinal disorders, hemorrhage, and hearing loss especially in younger patients. 
Furthermore, combined treatment with other sensitizing agents is an effective strategy to overcome cisplatin resistance (Shaloam et al., 2014).

Boswellia species (Burseraceae), which are trees native to Ethiopia, Somalia, India, and Arabic peninsula, produce a gum resin that is known as olibanum (frankincense). This gum resin has long been used in Ayurvedic and traditional Chinese medicine to treat a variety of health aspects ( $\mathrm{Ni}$ et al., 2012) such as inflammatory and arthritic diseases (Liu et al., 2002). The search for the active principles of the resin resulted in the isolation of boswellic acids that belong to ursaneand oleanane-type pentacyclic triterpenes (Safayhi et al., 1997). Recent studies suggested that gum resins of Boswellia species contain active ingredients that have anti-cancer activity ( $\mathrm{Ni}$ et al., 2012). Volatile oils prepared from the gum resin traditionally used for aromatic therapy has also been shown to have tumor cell-specific anti proliferative and pro-apoptotic activities. It was demonstrated that Boswellia sacra volatile oils (sesquiterpenes and monoterpenes) has tumor cell-specific cytotoxicity in multiple cancer cell types (Suhail et al., 2011). Results from preliminary clinical observations suggest that Beswellia SP volatile oils may be a valuable therapeutic agent for treating a variety of cancers. These oil are highly effective in suppressing proliferation and inducing cytotoxicity of various pancreatic cancer cell lines; and these in vitro activities correlate with the repression of cell cycle regulators and activation of the caspase pathway (Ni et al. 2012).

In the present study we have investigated the effect of natural chemo sensitizer Boswellic acid alone and in combination with cisplatin on HCC induced by DEN.

\section{MATERIALS AND METHODS}

\subsection{Chemical and antioxidant}

Boswellic acid was purchased from Advance Physician Formulas Inc. (California, USA) in tablet form, cisplatin was purchased from Tarshouby Pharmacy (Mansoura, Egypt), diethyl nitrosamine (DEN) used in this study was purchased from Sigma Chem. Co., (St. Louis, U.S.A) and all other chemicals were of analytical grade and were obtained from standard commercial suppliers.

\subsection{Experimental animals}

Sixty male albino rats (170-220 g), aged about 4 weeks, and were used in this study. Animals were obtained from the National Centre for
Radiation Research and Technology (NCCRT), Cairo, Egypt. Animals were housed in cages and maintained under standard conditions of ventilation, temperature and humidity. Animals received standard food pellets and water ad libitum. All animal treatment procedures conformed to the National Institutes of Health (NIH) guidelines.

\subsection{Preparation and administration of dosage}

Hepatocellular carcinoma was induced by administration of $(20 \mathrm{mg} / \mathrm{kg}$ b.wt/day) orally of DEN dissolved in 0.9 saline five times per week for six weeks according to (Balamurugan et al., 2012). Boswellic acid was administered at a dose level of $(500 \mathrm{mg} / \mathrm{kg} \mathrm{b} . \mathrm{wt} /$ day $)$ orally from the seventh week to the end of tenth week (Mona, 2016). Cisplatin was administered daily at a dose level of $(1.5 \mathrm{mg} / \mathrm{kg}$ b.wt/ i.p) from the seventh week until the end of tenth week (Abass et al., 2018).

\subsection{Experimental design}

Rats were divided randomly into 6 groups, 10 each, G1 (Control): Normal healthy control animals, G2 (Cisplatin): animals received cisplatin for four weeks, G3 (diethyle nitrosamine): animals received DEN orally for six weeks, G4 (diethyle nitrosamine + cisplatin): animals received DEN then treated with cisplatin, G5 (diethyle nitrosamine + Boswellic acid): animals received DEN then treated with Boswellic acid and G6 (diethyle nitrosamine + Cisplatin + Boswellic acid): animals received DEN then treated with cisplatin and Boswellic acid.

\subsection{Biochemical analysis}

\subsubsection{Blood:}

Blood samples were collected by heart puncture in dry, clean test tubes and allowed to clot for $30 \mathrm{~min}$ and serum was separated by centrifugation at 3000 r.p.m for $15 \mathrm{~min}$. The serum was separated by automatic pipette and received in dry sterile tubes, processed directly for ALT , AST (Reitman et al., 1957), and Albumin (Lowry, 1951) determination

\subsubsection{Liver:}

Rats were decapitated to collect liver samples for preparation of tissue homogenates where 100 mg tissue was rinsed with $1 \mathrm{X}$ PBS, homogenized in $1 \mathrm{ml}$ of $1 \mathrm{X}$ PBS and stored overnight at $-20^{\circ} \mathrm{C}$. After two freeze-thaw cycles were performed to break the cell membranes, the homogenates were centrifuged for 5 minutes at $5000 \mathrm{x} \mathrm{g}, 2-8^{\circ} \mathrm{C}$. 
The supernatant was removed and assayed immediately for estimation of TGF-b1 (Rat TGFb1 ELISA kit purchased from MyBiosource, Inc. (USA), catalog no. MBS824788), BCL2 (Rat BCL2 ELISA kit purchased from MyBioSource, Inc. (USA), catalog no. MBS704330), NF-k $\beta$ (Rat NF-k $\beta$ ELISA kit purchased from MyBioSource, Inc. (USA), catalog no. MBS043224), and Caspase.3 (rat caspase-3 ELISA kit purchased from MyBioSource, Inc. (USA), catalog no. MBS700575).

\subsection{Histopathological examination}

The liver tissue were rapidly dissected and excised rinsed in saline solution. The tissues were fixed with $4 \%$ paraformaldehyde and paraffinembedded sections were subjected to standard hematoxylin and eosin staining and then examined by light microscopy. Hepatic steatosis was measured by staining of 8 -mm thick frozen sections with Oil-Red-O (Sigma-Aldrich)

\subsection{Statistical analysis}

The SPSS (version 25) was used in data analysis. Data were analyzed with one-way analysis of variance (ANOVA) followed by a post hoc test (Duncan alpha) for multiple comparisons. The data were expressed as mean \pm standard error (S.E). P values $<0.05$ were considered to be statistically significant

\section{RESULTS}

\subsection{Results of Biochemical analysis}

A significant increase was recorded in Serum alanine aminotransferase (ALT) and aspartate aminotransferase (AST) activity, as well as hepatic transforming growth factor-beta 1 (TGFb1), B-cell lymphoma 2 (BCL-2) and nuclear factor kappa $\beta$ (NF-k $\beta$ ) concentration however a significant decrease in serum Albumin concentration and liver caspase. 3 activity were observed in DEN-induced HCC in rats when compared with control normal group. Intraperitoneal administration with Cisplatin to control rats resulted in a significant decrease in Serum ALT and AST activity, a significant decrease in TGF-b1, BCL2 and NF-k $\beta$ concentrations and a significant increase in ALB and Caspase. 3 when compared with control normal group. Treatment with Cisplatin and Boswellic acid to DEN rats ameliorate the levels of different parameters when compared with control DEN non-treated group.

\subsection{Results of Histopathological examination}

A liver of rat receiving DEN showing Patchy inflammatory infiltrate associated with dysplastic changes, dilated blood vessels and Perivascular inflammatory infiltrate associated with carcinoma formation, all were recorded in (Fig.3). While treatment with Cisplatin or Boswellic acid showed hepatocellular carcinoma with moderate degenerative changes, scattered inflammatory infiltrate all were recorded in fig $(4,5)$, but a liver of rat treated with cisplatine + Boswellic acid after receiving DEN showing marked degenerative changes tumor tissue necrosis all were recorded in fig (6)

Table (1) Effect of Boswellic acid and/or cisplatin administration on serum ALT, AST activities and albumin concentration in diethyl nitrosamine -induced HCC in rats

\begin{tabular}{lccc}
\hline Experimental groups & $\begin{array}{c}\text { ALT } \\
(\mathrm{U} / \mathrm{L})\end{array}$ & $\begin{array}{c}\text { AST } \\
(\mathrm{U} / \mathrm{L})\end{array}$ & $\begin{array}{c}\text { ALB } \\
(\mathrm{g} / \mathrm{dl})\end{array}$ \\
\hline G1: Control & $43.1 \pm 2.25^{\mathrm{f}}$ & $38.0 \pm 7.5^{\mathrm{f}}$ & $4.11 \pm 0.044^{\mathrm{a}}$ \\
G2: Cisplatin & $167 \pm 5.6^{\mathrm{b}}$ & $253.2 \pm 7.93^{\mathrm{c}}$ & $3.63 \pm 0.033^{\mathrm{b}, \mathrm{d}}$ \\
G3: diethyl nitrosamine & $213.2 \pm 7.25^{\mathrm{a}}$ & $334.7 \pm 6.88^{\mathrm{a}}$ & $2.79 \pm 0.052^{\mathrm{e}}$ \\
G4: diethyl nitrosamine + Cispaltin & $116.3 \pm 5.9^{\mathrm{d}}$ & $237.2 \pm 9.14^{\mathrm{c}}$ & $3.91 \pm 0.066^{\mathrm{a}, \mathrm{b}}$ \\
G5: diethyl nitrosamine + Boswellic acid & $83.2 \pm 4.1^{\mathrm{e}}$ & $211.4 \pm 4.66^{\mathrm{d}}$ & $3.93 \pm 0.098^{\mathrm{b}, \mathrm{c}}$ \\
G6:diethyl nitrosamine + Cispaltin + & $151.4 \pm 6.24^{\mathrm{c}}$ & $208 \pm 8.66^{\mathrm{d}}$ & $3.82 \pm 0.061^{\mathrm{b}, \mathrm{c}}$ \\
Boswellic acid & & &
\end{tabular}

Data are presented as (Mean \pm S.E).S.E $=$ Standard error. Mean Value with different superscript letters in the same column are significantly different at $(\mathrm{P} \leq 0.05)$

Table (2) Effect of Boswellic acid and/or Cisplatin administration on liver tissue TGF-b1, BCL-2, NF- k $\beta$ concentrations and Caspase-3 activity in diethyl nitrosamine -induced HCC in rats 


\begin{tabular}{|c|c|c|c|c|}
\hline Experimental groups & $\begin{array}{c}\text { TGF-B1 } \\
\text { (pg/ml/g.tissue) }\end{array}$ & $\begin{array}{c}\text { BCL2 } \\
\text { (ng/ml/g.tissue) }\end{array}$ & $\begin{array}{c}\mathrm{NFKb} \\
\text { (pg/ml/g.tissue) }\end{array}$ & $\begin{array}{c}\text { Caspase } .3 \\
\text { (ng/ml/g.tissue) }\end{array}$ \\
\hline G1: Control & $63.5 \pm 2.64^{\mathrm{a}}$ & $33.93 \pm 1.47^{\mathrm{e}}$ & $54.66 \pm 0.775^{\mathrm{f}}$ & $2.14 \pm 0.08^{\mathrm{d}, \mathrm{e}}$ \\
\hline G2: Cisplatin & $87.36 \pm 13.15^{\mathrm{c}, \mathrm{d}}$ & $31.26 \pm 1.18^{\mathrm{e}}$ & $60.87 \pm 5.42^{\mathrm{f}}$ & $4.62 \pm 0.091^{\mathrm{c}}$ \\
\hline G3: diethyl nitrosamine & $200.7 \pm 10.15^{\mathrm{a}}$ & $127.4 \pm 2.99^{\mathrm{a}}$ & $166.7 \pm 3.873^{\mathrm{a}}$ & $1.54 \pm 0.178^{\mathrm{e}}$ \\
\hline G4: diethyl nitrosamine + Cispaltin & $107.8 \pm 3.84^{b c}$ & $80.9 \pm 5.1^{\mathrm{c}}$ & $110.66 \pm 1.61^{\mathrm{b}, \mathrm{c}}$ & $6.54 \pm 0.18^{b}$ \\
\hline G5: diethyl nitrosamine + & $101.56 \pm 2.79^{\mathrm{c}, \mathrm{d}}$ & $92.96 \pm 2.29^{b}$ & $104.1 \pm 1.62^{\mathrm{c}}$ & $3.41 \pm 0.21^{\mathrm{c}, \mathrm{d}}$ \\
\hline \multicolumn{5}{|l|}{ Boswellic acid } \\
\hline $\begin{array}{l}\text { G6:diethyl nitrosamine }+ \text { Cispaltin } \\
+ \text { Boswellic acid }\end{array}$ & $86.3 \pm 1.65^{c}$ & $41.9 \pm 1.72^{\mathrm{d}}$ & $77.03 \pm 0.63^{\mathrm{e}}$ & $11.1 \pm 0.78^{\mathrm{a}}$ \\
\hline
\end{tabular}

TGF-b1: liver transforming growth factor-beta 1, BCL-2: B-cell lymphoma 2, NF-k $\beta$ : nuclear factor kappa $\beta$ and Caspase.3. Data are presented as (Mean \pm S.E).S.E $=$ Standard error. Mean Value with different superscript letters in the same column are significantly different at $(\mathrm{P} \leq 0.05)$

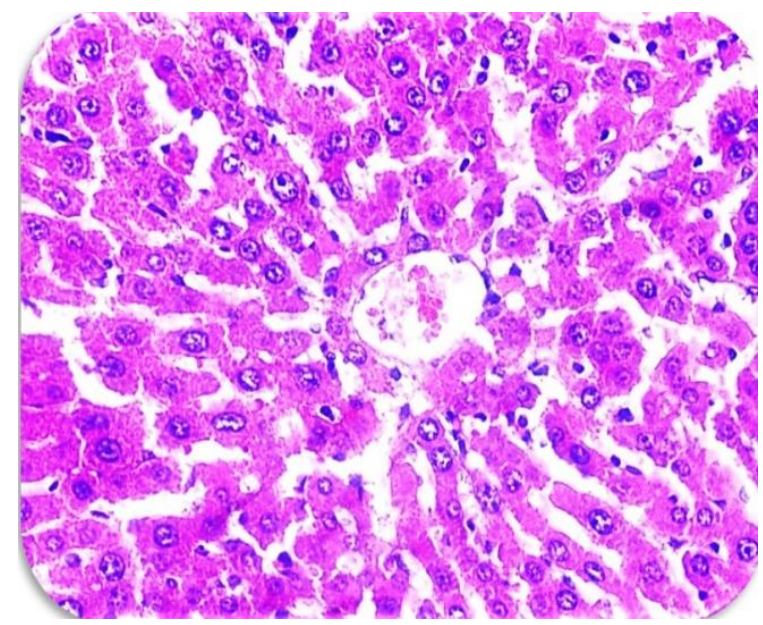

Fig (1) normal rat liver tissues (H\&E, 400X)

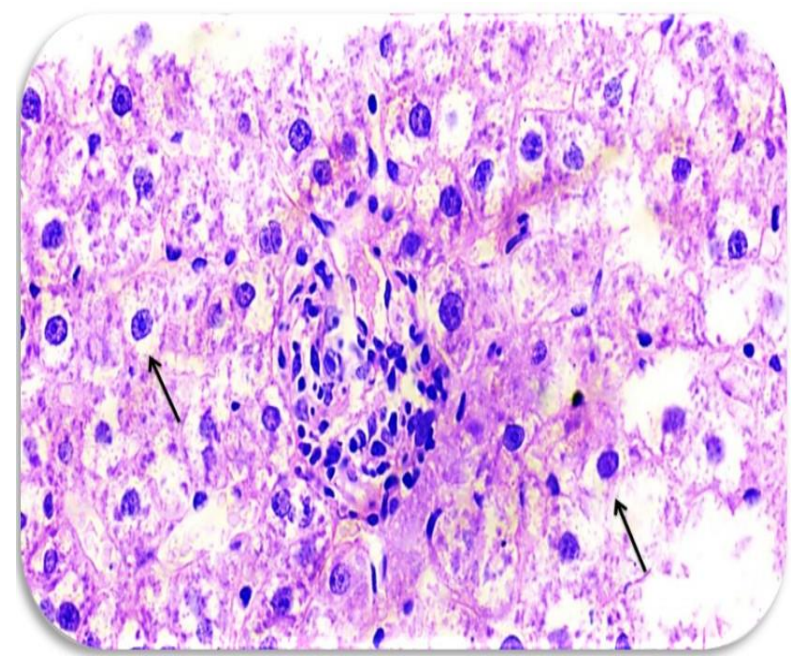

Fig (2) A liver tissues of rat receiving CIS showing degenerative changes, dissolution of hepatic cords and portal inflammatory infiltrate (H\&E, 400X)

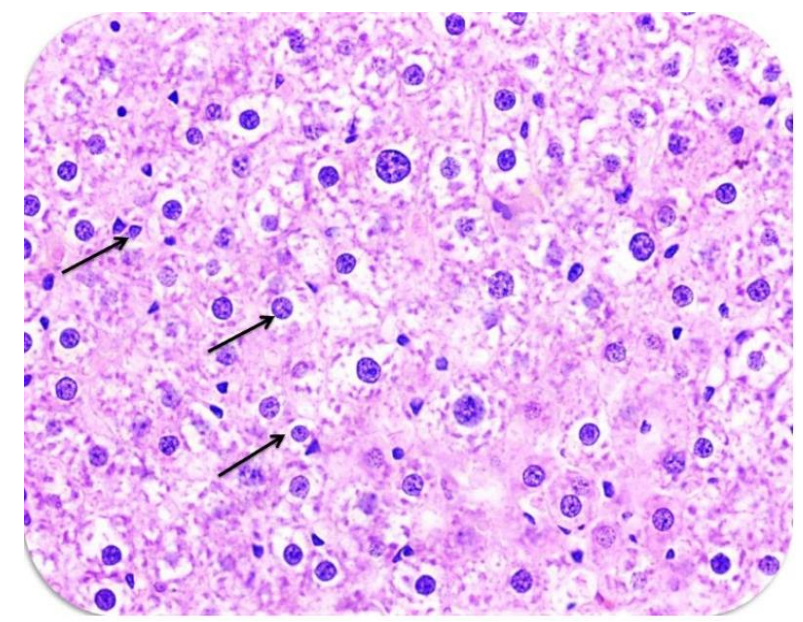

Fig (3) A liver tissues of rat receiving DEN showing hepatocellular carcinoma (note the cellular and nuclear pleomorphism, irregular nuclear membranes, coarse chromatin and nuclear inclusions) (H\&E, 400X)

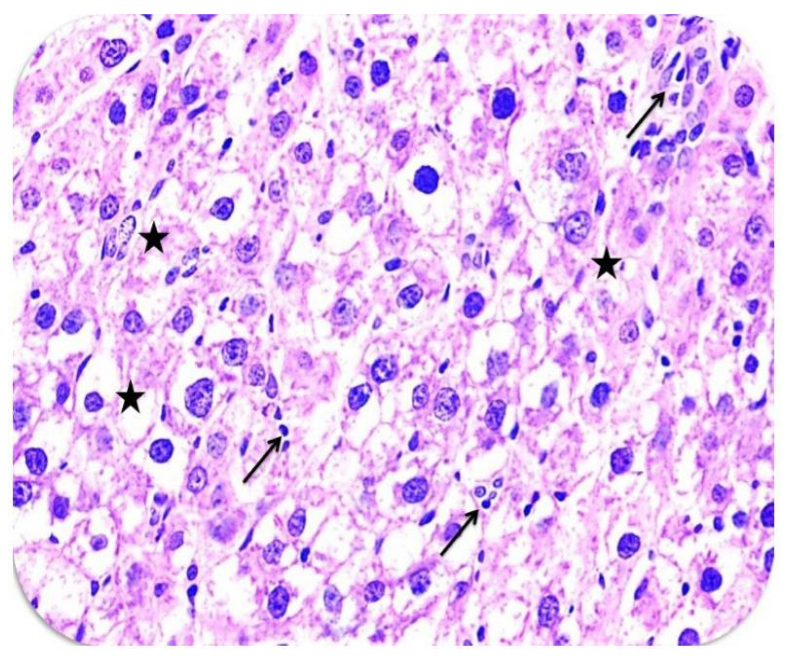

Fig (4) A liver of rat treated with CIS after receiving DEN showing hepatocellular carcinoma with moderate degenerative changes and scattered inflammatory changes (H\&E, 400X) 


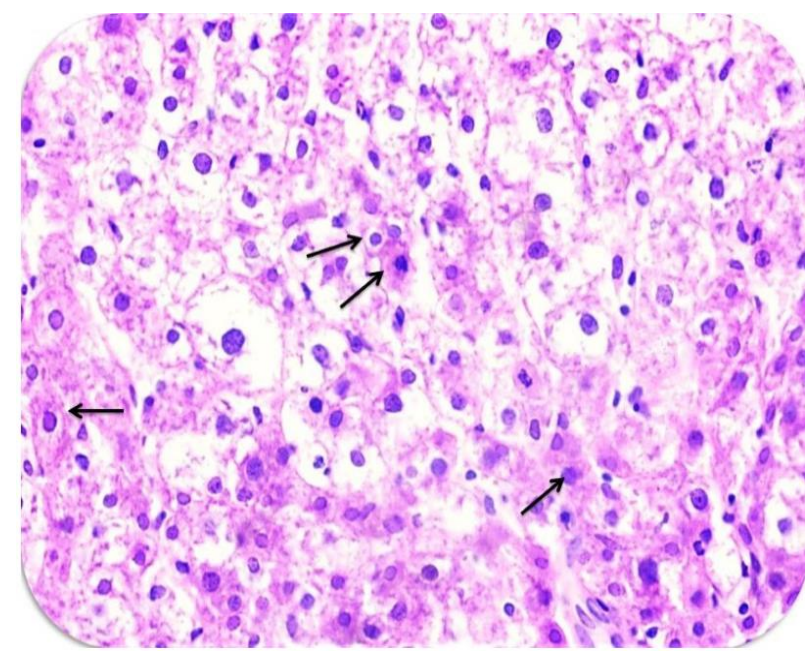

Fig (5) A liver of rat treated with BOS after receiving DEN showing hepatocellular carcinoma with degenerative changes and apoptosis (H\&E, 400X)

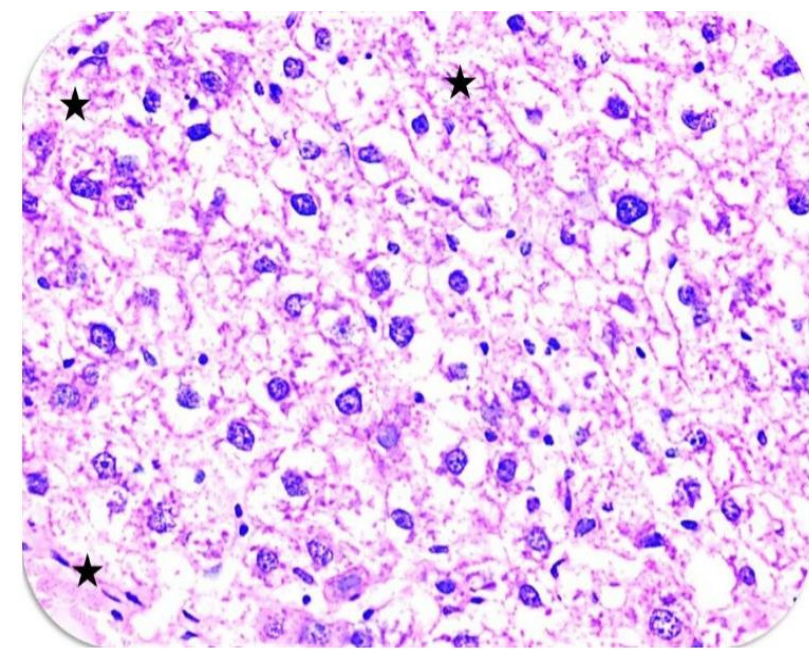

Fig (6) A liver of rat treated with CIS and BOS after receiving DEN showing hepatocellular carcinoma with marked degenerative changes and area of tumor tissue necrosis (H\&E, 400X)

\section{DISCUSSION}

Hepatocarcinogenesis is a multistep, multistage process that involves genetic and epigenetic alterations that ultimately lead to malignant transformation of hepatocytes. Several animal models have been reported that mimic different steps leading to HCC. These models have helped to identify molecular mechanisms that underlay the development of HCC including genetically modified mouse models, transgenic models expressing viral genes, transgenic mice overexpressing oncogenes and transgenic models over-expressing growth factors. Although valuable in facilitating detailed investigation of molecular pathways, the genetically modified animal models have been shown to vary significantly in their pattern of HCC development. Of the chemically induced HCC animal models, the $\mathrm{N}$-nitrosodiethylamine (DEN) based models are the most widely used and accepted (Bakiri et al., 2013). Diethyl nitrosamine (DEN), a strong hepatocarcinogen, was reported induce aberrations in the nuclear enzymes engaged in DNA repair and replication (Bhosale et al., 2002). Metabolic activation of DEN yields pro-mutagenic adducts, O6-ethyl deoxy guanosine and 04 and O6-ethyl deoxy thymidine in liver, leading to hepatocarcinogenesis (Verna et al., 1996). DEN liver model cancer is one of the most commonly used experimental models in hepatocarcinogenesis (Ha et al 2001). Liver cell destruction results in the leaking out of tissue contents into the blood stream (Mahmoud, 2011). When the liver cell plasma membrane is damaged, numerous enzymes normally located in the cytosol are released into the blood stream (Rajesh et al., 2004), and their estimation in serum is a useful quantitative marker to indicate hepatocellular damage (Hwang et al., 2001). In our study Administration of DEN to normal rats exhibited a significant increase in ALT and AST activities when compared with control normal. This was in agreement with (Moawad et al., 2018) who showed that DEN administration caused significant elevation in the liver enzymes due to the increased permeability of plasma membrane or cellular necrosis leading to leakage of the enzymes to the blood stream (Atef, 2012). In our study a significant decrease in Serum ALB concentrations was observed in DEN-induced HCC in rats when compared with control normal group. This agree with Bağırsakçı et al., (2017) who reported that larger HCCs are associated with lower albumin levels. Transforming growth factor (TGF)- $\beta$ signaling has been shown to play an important role in epithelial-mesenchymal transition (EMT)-related miRNAs in HCC and their oncogenic or tumor suppressive functions. TGF- $\beta$ induces cells to lose their epithelial characteristics and to acquire migratory behavior (Tae-Su et al., 2018). The effects of HCC stages on development of fibrosis were evaluated by quantifying TGF-1 expression and percentage of fibrosis (\%) (Andrea et al., 2015). In this study administration of DEN to normal rats exhibited a significant increase in TGF-B1 when compared with control normal. These results were in accordance with those reported by (Andrea et al., 2015). In accordance with our study, (Rajasekaran et al., 2011) reported that DEN HCC models registered significantly higher expression of apoptotic regulators, such as $\mathrm{Bcl} 2$ (anti-apoptotic) in addition Faisal et al., 2018 reported elevated expression of $\mathrm{Bcl} 2$ in DEN-induced HCC rats. Nuclear Factor kappa B (NF-k $\beta$ ) was identified by 
David Baltimore and Coworkers in 1986 as a factor in the nucleus of $B$ cells that binds to the enhancer of the kappa light chain of immunoglobulin. NF-k $\beta$ is a transcription factor that serves as a master switch for turning on certain immune and inflammatory responses. NF$\mathrm{k} \beta$ alters cell behavior in many ways; it inhibits apoptosis (programmed cell death), increases cell proliferation and increases inflammatory and immune response. Recent evidence suggests that activation of NF-k $\beta$ contributes to the development of several types of human cancer (Mamatha et al., 2016). This study showed significant decrease in Casp-3 activity in DEN group compared to normal animals as reported before this is in accordance with (Amina et al., 2017). Also, the decrease in caspase -3 expression was confirmed by Soha et al (2018), who concluded that caspase -3 activity expression in tumor tissues were significantly lower than those in non-tumor tissue. The present study showed that treatment of Cisplatin and Boswellic acid significantly reduced $\mathrm{HCC}$ as evidenced by enhancement of the Histopathological finding and improvement of liver functions. The obtained data demonstrated in table (1) revealed that, administration of Boswellic acid and Cisplatin to DEN treated rats exhibited a significant decrease in serum ALT and AST when compared with DEN induced HCC groups, These results were in accordance with those reported by, Khan et al., 2014, treatment with Boswellic acid induced the increased activities of these enzymes and were normalized. This suggested that the Boswellic acid played a role in parenchymal cell regeneration in liver, thus protecting membrane integrity, thereby decreasing enzyme leakage. Khan et al., 2014, reported that Boswellic acids can induce apoptosis in cancer cells through activation of caspase- 3 and up regulation of cell death receptors DR4 and TNF-R1 levels, leading to caspase- 8 activation Bhushan et al., 2007. A study by Syrovets et al., 2005 reported the effect of BA on NF- $\mathrm{BB}$, a transcription factor associated with malignant phenotype as well as chemoresistance of various cancers, convey inhibition of NF-kappaB. Jian-Jun et al., 2002, demonstrated for the first time that the activities of caspase-3, caspase- 8 and caspase- 9 were activated by boswellic acids, indicating that both death receptor-related apoptotic pathway and the mitochondria-related pathway were activated. Liu et al. (2002) reported that boswellic acids strongly induce apoptosis through activation of caspase-3, -8 , and -9 and cleavages of the poly ADP ribose polymerase (PARP) enzyme in hepatoma HepG2 cells. Boswellic acids could regulate tumor cell viability by activating a variety of mechanisms. As, they could arrests cancer cells at the G1 phase of cell cycle, suppresses levels of cyclin D1 and E, CDK 2 and 4, and RB phosphorylation, as well as elevates the expression of p21 through a p53independent pathway (Syrovets et al., 2005 and Liu et al., 2006). Moreover, boswellic acids can activate additional pathways in cancer cells. boswellic acids can inhibit NF-k $\beta$ activities in tumor cells (Park et al., 2011 and Kumar et al., 2012). In the light of the present results, Cisplatin causes increase in Csapase. 3 activity that come in accordance with Shang et al., 2018 who found that, caspase-3 activity assay results showed that cisplatin significantly activated caspase- 3 in LM3 cells, suggesting that cisplatin induced apoptosis of LM3 cells ( $p<0.05)$.

\section{CONCLUSION}

Our data provides convincing evidence that combination treatment is effective against HCC by induction of apoptosis. While the currently available chemotherapeutic options are associated with unavoidable adverse effects, oral Boswellic acid provides hope as a useful anticancer agent with significantly lower toxicity on normal liver tissue. Thus the use of synergistically acting Boswellic acid and Cisplatin combination therapy could be a novel strategy for the treatment for HCC and probably will have lesser toxicity compared to currently used regimens

\section{REFERENCES}

Abass, S.A., El-Hamid, N.M.A., Abouzed, T.K., El-Shishtawy, M.M., 2018: Chemosensitizing effect of Alpinia officinarum rhizome extract in cisplatintreated rats with hepatocellular carcinoma. Biomed Pharmacother. 101:710-718. doi: 10.1016/j.biopha.2018.02.128.

Abd-Elsalam, S., Elwan, N., Soliman, H., Ziada, D., Elkhalawany, W., Salama, M., Hawash, N., Arafa, M., Badawi, R., Shehata, W.M., Khalil, H.S., Elmashad, N., 2018: Epidemiology of liver cancer in Nile delta over a decade: a single-center study. South Asian J Cancer; 7: 24-6.

Akhurst, R.J., Hata, A., 2012: Targeting the TGF $\beta$ signalling pathway in disease. Nat Rev Drug Discov; 11:790- 811.

Amina, M., Somaya, M., Sawsan, E., Eman, K., Mustafa, M., 2017: Evaluation of the antitumor activity of platinum nanoparticles in the treatment of hepatocellular carcinoma 
induced in rats. Tumor Biology: DOI: $10.1177 / 1010428317717259$.

Andrea, J.M., Graziella, R., Silvia, B., Carlos. T.C., Claudio, A.M., Jose, L.M., Javier, G.G., Norma, P.M., 2015: Oxidative stress and cell damage in a model of precancerous lesions and advanced hepatocellular carcinoma in rats Toxicology Reports 2; 333-340. www.elsevier.com/locate/toxrep

Bağırsakçı, E., Şahin, E., Atabey, N., Erdal, E., Guerra, V., Carr, B.I., 2017: Role of Albumin in Growth Inhibition in Hepatocellular Carcinoma. Oncology; 93(2):136-142. doi: 10.1159/000471807.

Bakiri, L., Wagner, E.F., 2013: Mouse models for liver cancer molecular oncology 7 206-223. Federation of European Biochemical Societies.

http://dx.doi.org/10.1016/j.molonc.2013.01. 005

Bhosale, P.M.L., Ignle, A.D., Gadre, R.V., Rao, K.V.K., 2002: Protective effect of Rhodotorula glutinis NCIM3353 on the development of hepatic preneoplastic lesions. Current Science; 83:303-308.

Bhushan, S., Kumar, A., Malik, F., 2007: A triterpenediol from Boswellia serrata induces apoptosis through both the intrinsic and extrinsic apoptotic pathways in human leukemia HL-60 cells," Apoptosis, vol. 12, no. 10, pp. 1911-1926, 2007

Elghazaly, H., Gaballah, A., Bahie Eldin, N., 2019: Clinic-pathological pattern of hepatocellular carcinoma (HCC) in Egypt. https://academic.oup.com/annonc/article abstract/29/suppl_5/mdy151.018/5039483.

El-Zayadi, A.R., Badran, H.M., Barakat, E.M., Attia, Mel-D., Shawky, S., Mohamed, M.K., Selim, O., Saeid, A., 2005: Hepatocellular carcinoma in Egypt: a single center study over a decade. World J Gastroenterol; 11:5193-8.

Fabregat, I., Moreno-Càceres, J., Sánchez, A., Dooley, S., Dewidar, B., Giannelli, G., Ten Dijke, P., 2016: TGF- $\beta$ signalling and liver disease. FEBS J; 283:2219-2232.

Faisal, A.A., Mohammed, A.E., Ahmed, A.H., Ayman, A.S., Islam, M.S., Eman, S.E., Abdelnaser, A.B., Saleh, A., 2018: Potential Effect of Exosomes Derived from Cancer Stem Cells and MSCs on Progression of DEN-Induced HCC in Rats. Hindawi Stem Cells International, Article ID 8058979, .

Fazal, K., Tariq J.K., Gauthaman, K., Peter N.P., Adeel, C.,Adel, A., Taha K., Elie, B., Mohammed A., 2017: Anti-cancer effects of Ajwa dates (Phoenix dactylifera L.) in diethylnitrosamine induced hepatocellular carcinoma in Wistar rats. Khan et al. BMC Complementary and Alternative Medicine 17:418 DOI 10.1186/s12906-017-1926-6.

Gaigai, L., Yuxue Z., Chunchun, L., Daqian, X., Rui, Z., Yuan, C.h, Yi, P., Cheng, H., Yan, C., 2014: Luteolin Alleviates Alcoholic Liver Disease Induced by Chronic and Binge Ethanol Feeding in Mice. The Journal of Nutrition. doi: 10.3945/jn.114.193128.

Giannini, E.G., Testa, R., Savarino, V., 2005: Liver enzyme alteration: a guide for clinicians. CMAJ; 172:367-79.

Ha, W.S., Kim, C.K., Song, S.H., Kang, C.B., 2001: Study on mechanism of multistep hepatotumorigenesis in rat: development of hepatotumorigenesis. J Vet Sci; 2:53-58.

Jian-Jun, L., Åke, N., Stina, O., Vladimir, B., Wan-Zhou, Z., Rui-Dong, D., 2002: Boswellic acids trigger apoptosis via a pathway dependent on caspase-8 activation but independent on Fas/Fas ligand interaction in colon cancer HT-29 cells Carcinogenesis vol.23 no.12 pp.2087-2093.

Khan, M.A., Singh, M., Khan, M.S., Najmi, A.K., Ahmad, S., 2014: Caspase mediated synergistic effect of Boswellia serrata extract in combination with doxorubicin against human hepatocellular carcinoma. Biomed Res Int 2014; 2014: 294143.

Kumar, A., Shah, B.A., Singh, S., 2012: Acyl derivatives of boswellic acids as inhibitors of NF-kB and STATs. Bioorg Med Chem Lett, 22, 431-5.

Liu, J.J., Huang, B., Hooi, S.C., 2006: Acetylketo- $\beta$-boswellic acid inhibits cellular proliferation through a p21-dependent pathway in colon cancer cells. $\mathrm{Br} J$ Pharmacol, 148, 1099- 107.

Liu, J.J., Nilsson, A., Oredsson, S., 2002: Boswellic acids trigger apoptosis via a pathway dependent on caspase-8 activation but independent on Fas/Fas ligand interaction in colon cancer HT-29 cells. Carcinogenesis, 23, 2087-93.

Mamatha, S., Shanmuga, R.C., 2016: Function of Nuclear Factor kappa B (NF-kB) in human diseases-A Review. South Indian Journal Of Biological Sciences; 2(4); 368-387

Moawad, M., Hegazy, A.E., Ghada, M.N., Sakr, S.A., Handa, A.K., Nasr, M.I., 2018: Evaluation of the protective effect of Jojoba natural products on hepatoxicity of diethyle nitrosamine in rats, Egypt. J. Genet. Cytol., 47: 193-201, (www.esg.net.eg). 
Mohamed, S.E., Raafat, S., Hanan, H.S., Said, H.A., Sherief, A., Walaa, E., Loai, M., Hala, M.E., Haidy, K., 2016: Alfatoxin as an environmental risk factor attributable to liver cancerin Nile delta. Indian Journal of Medical Research and Pharmaceutical Sciences; 3(4) ISSN: ISSN: 2349-5340 DOI: 10.5281/zenodo.

Mona Kamal Tawfik. 2016: Anti-aggregatory effect of boswellic acid in high-fat fed rats: involvement of redox and inflammatory cascades, Arch Med Sci; 12, 6: 1354-1361.

Ni, X., Suhail, M.M., Yang, Q., 2012: Frankincense essential oil prepared from hydrodistillation of sacra gum resins induces human pancreatic cancer cell death in cultures and in a xenograft murine model. BMC Complement Altern. Med, 12, 253

Okuda, M., Li, K., Beard, M.R., 2002: Mitochondrial injury, oxidative stress, and antioxidant gene expression are induced by hepatitis $\mathrm{C}$ virus core protein. Gastroenterology; 122:366-75.

Park, B., Sung, B., Yadav, V.R., 2011: Acetyl-11keto-bboswellic acid suppresses invasion of pancreatic cancer cells through the downregulation of CXCR4 chemokine receptor expression. Int J Cancer, 129, 2333.

Rajasekaran, D., Elavarasan, J., Sivalingam, M., Ganapathy, E., Kumar, A., Kalpana, K., Sakthisekaran, D., 2011: Resveratrol interferes with N-nitrosodiethylamineinduced hepatocellular carcinoma at early and advanced stages in male Wistar rats. MOLECULAR MEDICINE REPORTS 4: 1211-1217.

Safayhi, H., Sailer, E.R., 1997: Anti-inflammatory actions of pentacyclictriterpenes. Planta Med, 63, 487-93.

Shaloam D., and Paul B.T., 2014: Cisplatin in cancer therapy: molecular mechanisms of action. Eur J Pharmacol. 0: 364-378. doi:10.1016/j.ejphar.2014.07.025. NIH.

Shang, M.J., Hong, D.F., Hu, Z.M., Zhang, C.W., $\mathrm{Wu}$,

W.D., 2018: Cisplatin induces apoptosis of hepatocellular carcinoma LM3 cells via down-regulation European Review for Medical and Pharmacological Sciences; 22: 382-387
Shen, Y., Wei, Y., Wang, Z., Jing, Y., He, H., Yuan, J., Li, R., Zhao, Q., Wei, L., Yang, T., Lu, J., 2015: TGF- $\beta$ regulates hepatocellular carcinoma progression by inducing Treg cell polarization. Cell Physiol Biochem; 35:1623-1632.

Soha, M.H., Saad, M. E., Sahar, S.A., 2018: CASPASE-3 and FAS-L expression and their roles as signal transduction in hepatocellular carcinoma. Bulletin of the National Nutrition Institute of the Arab Republic of Egypt.

Suhail, M.M., Wu, W., Cao, A., 2011: Boswellia sacra essential oil induces tumor cellspecific apoptosis and suppresses tumor aggressiveness in cultured human breast cancer cells. BMC Complement Altern Med, 11, 129.

Syrovets, T., Buchele, B., Krauss, C., Laumonnier, Y., Simmet, T., 2005: Acetylboswellic acids inhibit lipopolysaccharidemediated TNF-alpha induction in monocytes by direct interaction with IkappaB kinases, J. Immunol. 174. 498506.

Tae-Su, H., Hyun, S.B., Keun, H., Hyun-Soo, C., 2018: The Epigenetic Regulation of HCC Metastasis. International Journal of Molecular Sciences, 19, 3978; doi:10.3390/ijms19123978.Tarao, K., Rino, Y., Takemiya, S., 2002: Close association between high serum ALT and more rapid recurrence of hepatocellular carcinoma in hepatectomized patients with $\mathrm{HCV}$-associated liver cirrhosis and hepatocellular carcinoma. Intervirology; 43:20-6.

Verna, L., Whysner, J., Williams, G.M., 1996: Nnitrosodiethylamine mechanistic data and risk assessment: bioactivation, DNA-adduct formation, mutagenicity, and tumor initiation. Pharmacol Ther; 71:57-81.

Wang, Z.X., Jiang, C.P., Cao, Y., 2015: Preoperative serum liver enzyme markers for predicting early recurrence after curative resection of hepatocellular carcinoma. Hepatobiliary Pancreat Dis Int; 14:178-85. 